\title{
Information Seeking Problems that May Occur Against Covid-19 Vacccine When it is Ready
}

\author{
Olowo Emmanuel Opeyemi ${ }^{1}$, Hamisah Hasan², Abdul Mua'ti ${ }^{3}$, Julia Wirza Mohd Zawawi ${ }^{4}$ \\ ${ }^{1}$ Doctoral Degree Student, ${ }^{2}$ Associate. Professor, ${ }^{3}$ Professor, ${ }^{4}$ Senior Lecturer, Department of Communication, \\ Faculty of Modern Languages and Communication, 43400 Univ. Putra Malaysia, Serdang, Selangor
}

\begin{abstract}
Information-seeking patterns of vaccine receivers have over time been determined their vaccine decisions. These patterns are mostly represented by their demographic representation. Therefore it is interesting to review how these demographic representations have affected vaccine choices in the past. This paper would serve as a guide to health officials, human communication experts and pharmaceutical companies in the development and distribution of Coronavirus vaccines when it is ready.
\end{abstract}

Keywords: Information seeking, Corona virus, Religion, Income, Side-effects, and Vaccine Hesitancy.

\section{Introduction}

The $8^{\text {th }}$ of December, 2019 foresaw the first reported case of Corona Virus Disease 2019 (COVID-19) in Wuhan, China ${ }^{[1]}$. By April $25^{\text {th }} 2020$ over 2.8 million cases and 200,000 deaths have been confirmed all over the world with the United states of America, Italy, China and Spain were countries with most reported cases ${ }^{[2]}$. More so as at the time of this study vaccine against or to prevent this pandemic is not available. However, the World Health Organization (WHO) were able to team up with global forces, the mainstream media, and the government to pass out "the kick out coronavirus" campaigns ${ }^{[3]}$. This message published in 18 languages were protrude as (i) hands, washing of hands generally with soap or alcohol-based solutions (ii) elbow, covering of mouth and nose with a bent elbow or tissue whilst sneezing or coughing (iii) Face, avoid touching your face especially the "T-Zone" to prevent virus from entering your body (iv) distance, social distancing is way to break the chain of the virus. Keep a safe space always (v)

\section{Corresponding Author:}

\section{Hamisah Hasan, PhD}

Associate. Professor, Department of Communication, Faculty of Modern Languages and Communication 43400 Univ. Putra Malaysia, Serdang, Selangor Tel: +6012-371 7054

e-mail: hamisah@upm.edu.my
Feel, it you feel unwell, please report to the local health authorities around you ${ }^{[4]}$. These measures could only serve as more of a preventive measure against the virus than a permanent cure or anti vaccine solutions that have been put in place to tackle past epidemic and pandemic crisis. COVID-19 does not just alter and stretch medical personals and systems it has broken the world's economy as stocks and oil prices are falling by the data ${ }^{[4]}$.

This chaos has led to an emergency call/need for vaccines against, and to cure COVID-19. Vaccine development is ridiculously expensive. normally it takes between 20-30 months for a vaccine to complete clinical trials and Food and Drug administration FDA approvals. the race is on for the first pharmaceutical com to develop an approved (COVID-19) vaccine, but at what cost? would it be affordable? These are questions this paper will try to collate together. For example, ${ }^{[5]}$ reported that over four thousand works have begun a trial for a century-old vaccine for tuberculosis to see it if it could serve as an immune build up against the virus but not a cure. The assumption of this vaccine is that if your immune are stronger, it would limit the fatality of the virus if you were infected. Subsequently, the Murdoch Children's Research Institute (MCRI) explained that the vaccine results were expected in about six months' time. Another by ${ }^{[5]}$ illustrated that COVID-19 is expected to be on the market in at least 18 months. Although leading pharmaceuticals like 'Inovio' explained that a DNA-based vaccine has begun pre-clinical trials (human 
test ready). More so GlaxoSmithKline are developing a protein vaccine "molecular Clamp" that enables COVID-19 to enter human cells. The United States company "Moderna" has already begun testing an RNAbased treatment ${ }^{[6]}$. On April the $20^{\text {th }}$ Dr.Jennifer Miller, Ph.D stated in an interview to abc NEWS that one of the challenges involved in the clinical trials for a COVID-19 vaccine is procurement of a vaccine that is responsive to population needs/demands as the vaccine would be needed all over the world when it is ready ${ }^{[5]}$. However, it is important to understand how people approach health related issues based on their information seeking behaviours.

Wilson defines 'information behaviour' or 'information seeking behaviour' as a need that arises in order to fill a knowledge quest or to satisfy an information need ${ }^{[7]}$.Case, ${ }^{[8]}$ explained that, an information need may consist or perceive a difference between an actual state of knowledge or an ideal state of knowledge. This information need might be satisfied by searching or seeking information from an informal or formal services or source of information, which might result in failure or success in finding that information. If this search for information is successful, the person might then make use of such information acquired to satisfy the need for it or transfer such a knowledge to another ${ }^{[10]}$. The race to develop a vaccine is much impressive, and the with the aid of technology one could be ready in 6-8 months. The questions remains that are manufactures putting into consideration everyone in the world and trying to learn from previous mistake?

would the manufacturers of this vaccine put into the consideration religious sentiments and beliefs during production? as we know people reject vaccines simply because it contains (religious) forbidden ingredients. For example, ${ }^{[9]}$ could be referred to as one of the pandemic era in medical history because of the outbreak of measles and pertussis. This event in similar fashion like the COVID-19 caused for social distancing and exclusion from work and school in the affected areas ${ }^{[11]}$.Although as at the arrival of the vaccine, there were certain relgious complications which influenced vaccine decisions ${ }^{[17]}$. A study by ${ }^{[19]}$ found that some groups in india refused their childern vaccinations due to relgious predictive factors. For the catholicis the most common issues regarding vaccinaions has been the moral reflection on vaccines derived from using cells of a voluntatry aborted fetus ${ }^{[18]}$. However, the catholic doctorines didn't directly cover this vaccination topic directly, it only expalins on the ability of human intellect and emphasises to always "save lives." The protestant on the other hand are of the view that vaccination is an act of lack of faith in God. This explains why side effects following vaccinations are seen as a punishment from God ${ }^{[17]}$ The Jewish have a contradicting view to that of the Orthodox, they believe that people should vaccinate based on the recommendations of the health care professionals ${ }^{[16]}$. The Islamic tradition forbids use of certain food "haram" add this irritations are transfer to vaccinations as well, as seen In the case of Islam vs vaccines which contained pig DNA ${ }^{[7]}$ These religions sentiments can/would be a major problem for vaccine developers should there be a break through with the vaccine against COVID-19. They would have to find a balance where all of the population are comfortable with the ideology of vaccination ${ }^{[12]}$.

Yes, the race to bit time and this pandemic means vaccines ought to be ready like yesterday, but would the emergency bypass for this vaccines not lead to another catastrophe in side effects? According to the study by the World Health Organization (WHO) in 2013 they explained that the public has a really tolerance to vaccine adverse reactions. Therefore, vaccines can only be administered when there are very rare or minor reactions reported ${ }^{[13]}$. Logically a vaccine that has passed all medical/clinical trials have been deem good enough by the appropriate authorities as good enough for the public. These vaccinations could be in oral or injection forms. Subsequently, such adverse effects like dizziness, fever, headache, pain, swelling, and loss of appetite [14]. With the race to create an emergency vaccine to help combat COVID-19 which should be out there in the market as soon as possible, pharmaceuticals need to be vary of the possible side effects that could follow such vaccine, because a severe reaction or complication might lead to an out-right of the vaccine ${ }^{[13]}$.

More so, we have people who believe non-medical exemption for vaccines. they were never vaccinated. if a vaccine is available, would they be forced to accept the vaccine even if it is against their right knowing full well that they could endanger the whole nation?

In the United States of America (USA) for example, there are states that allow nonmedical exemptions (NMEs). These emptions are allow children to be exempted from vaccines due to medically contradictory reasons ${ }^{[15]}$ More so, parents are allowed to be exempted based on their personal, philosophical and religious beliefs as NMEs are considered as a balance in child 
welfare and protection of parental rights and public health $^{[20]}$. In the State of Texas the main reason for NEMs has been philosophical exemptions. Although states like Oregon, Washington and California have made the process of ${ }^{[2] \text {. }}$

Lastly, would the vaccine be acceptable to $1 / 3$ of the world's population due to the cost of the vaccine? ${ }^{[6]}$ explained that, income can be categorized into two; i) High income countries, ii) low income countries [6], continued that high-income countries (HIC) are often of the opinion that vaccine is a victim of its own success. Parents in this category believe or argue that the decrease of Vaccine preventable diseases (VPD) means they don't need the vaccine anymore, as thus, the fear of receiving "useless vaccine" is more prominent that the fear of VPD. Low income countries on the other hand, still believe in the ideology of vaccination. So, it's really unclear as to why there is a decrease in acceptance amongst them ${ }^{[6] .[8]}$ in an article reported for the Los Angeles Times, explained that vaccine exemptions in more than 150 schools in Los Angeles rose above $8 \%$. Parents responsible for these emptions were those who earn an average of $\$ 94,500$. Hiltzik concluded that schools and government shouldn't allow these "rich" parents affect the herd immunity with their poor vaccine decisions ${ }^{[8]}{ }^{[21]}$ illustrated in their study that, Low income adults are more open to accepting vaccinations when compared to the high-income adults. also pointed out that, due to personal experience, with VPD most women view vaccination positively ${ }^{[22]}$.

\section{Conclusion}

As the world currently seek possible solutions to the COVID-19 pandemic, it is empirical for pharmaceutical to reflect on the possible determinates of vaccine hesitancy. A vaccine is only as useful as the acceptance rate. More so, given that the nature of this kind of vaccine that would be useful to everyone irrespective of their socio demographic representation. This is tricky because of the contagion rate of the pandemic. One cannot afford to leave out a certain heterogenous anti vaccine population. Questions of how the United Nations (UN) would enforce those against non-medical exemptions to take the vaccine when it is eventually ready is fascinating. Would the rights of private individuals be treated and put into consideration before the safety of the herd? How would they be convinced to accept the vaccine? As for religion, as observed above that might be a little flexible if the “forbidden' materials are not used in the procurement of the vaccine. However, the protestants who believe that vaccinations is against the almighty protection of God might also posit another complication. Lastly, due to the pandemic a lot of companies have been forced to lay off their employees. How affordable would the vaccine be that a family would not be forced to choose between their daily meal and vaccination? Affordability is a key essential in vaccine acceptance.

Conflict of Interest: There are no conflict of interest noted.

Ethical Clearance: Taken from Universiti Putra Malaysia Ethics Committee (JKEUPM). Ref noJKEUPM-2019-248.

Source of Funding: Self.

\section{References}

1. WHO, "Pass the message: Five steps to kicking out coronavirus," 2020. [Online]. Available: https:// www.who.int/news-room/detail/23-03-2020-passthe-message-five-steps-to-kicking-out-coronavirus.

2. F. Wu, S. Zhao, B. Yu, Y. Chen, W. Wang and e. al., "A new coronavirus associated with human respiratory disease in China," Nature, 2020.

3. COVID-19, "Coronavirus Pandemic cases," 2020. [Online]. Available: https://www.worldometers. info/coronavirus/.

4. C. Joanne, "Global stocks fall as Oil Dips Below \$20," 2020. [Online]. Available: https://www. wsj.com/articles/global-stock-markets-dow-upda te-3-30-2020-11584925602-11585531131.

5. K. Byron, "Austrialia enters 4,000 healthcare workers in trial for coronavirus vaccine," 2020. [Online]. Available: https://www.thestar.com. my/news/world/2020/03/26/australia-enters4000-healthcare-workers-in-trial-for-coronavirusvaccine.

6. M. Mark, "Coronavirus vaccine: How soon will we have one?," 2020. [Online]. Available: https:// www.weforum.org/agenda/2020/03/vaccinecovid-19-coronavirus-pandemic-healthcare/.

7. N. B. Angela, "Injecting healthy adults with live coronavirus provides moral dilemma, faster path to vaccine," 2020. [Online]. Available: https:// abcnews.go.com/Health/injecting-healthyadults-live-coronavirus-moral-dilemma-faster/ story? $\mathrm{id}=70331610$. 
8. U. A Knol M, "Large ongoing measles outbreak in a religious community in the Netherlands since May 2013," Euro Surveill, 2013.

9. H.. Ruijs WL, "The role of religious leaders in promoting acceptance of vaccination within a minority group: a qualitative study.," BMC Public Health, 2013.

10. G. M. Shrivastwa N, "Predictors of vaccination in India for children aged 12-36 months.," Vaccine, 2015.

11. E. Sgreccia, "Moral reflection on vaccines prepared from cells derived from aborted human foetus," Pontificial Academia Pro Vita., 2005.

12. Rabbinical, "Rabbinical Council of America. Statement on Vaccinations from the $\mathrm{OU}$ and Rabbinical Council of America," 2016. [Online]. Available: http://www.rabbis.org/news/article. cfm?id=105814.

13. J. D. Grabenstein, "What the world's religions teach, applied to vaccines and immune globulins," Vaccine, 2013.

14. WHO, "Adverse events following immunization," The World Health Organisation, 2013.

15. E. O. Olowo, H. Hamisah and W. M. Z. Julia, "Information Seeking and Trust on Vaccination Practices," Human Communication PACA, 2018.
16. S. K. McCauley, "Exploring the choice to refuse or delay vaccines: A national survey of parents of 6through 23-month olds," Academic Pediatre, 2012.

17. S. N. Omer SB, "Vaccine refusal, mandatory immunization, and the risks of vaccine-preventable diseases.," N Engl J Med., 2009.

18. R. Silverman, "No more kidding around: restructuring non-medical childhood immunization exemptions to ensure public health protection.," Ann Health Law, 2003.

19. N. Blank, A. Caplan and C. Constable, "Exempting schoolchildren from immunizations: states with few barriers had highest rates of nonmedical exemptions.," Health Aff (Millwood), 2013.

20. M. Hiltzik, "Rich, educated and stupid parents are driving the vaccination crisis," 15 December 2018. [Online]. Available: https://www.latimes. com/business/hiltzik/la-fi-mh-vaccination-crisis20140903-column.html.

21. P. Jeudin, E. Liveright, G. Marcela, C. Del and B. Rebecca, "Race, Ethnicity, and income factors impacting human papillomavirus vaccination rates," Clinical Therapeutics, p. 36, 2014.

22. E. Dube, M. Vivion and N. E. MacDonald, "Vaccine hesitancy, vaccine refusal and the anti-vaccine movement: Influence, impact and implications," Vaccines, 2015. 